\title{
Effect of Acidified Aerosols on Initial Corrosion Behavior of Q235 Carbon Steel
}

\author{
Miao-Ran Liu ${ }^{1,2} \cdot$ Xiao Lu $^{1,3} \cdot$ Qi Yin $^{1,3} \cdot$ Chen Pan $^{1} \cdot$ Chuan Wang $^{1} \cdot$ Zhen-Yao Wang $^{1}$
}

Received: 16 August 2018 / Revised: 12 October 2018 / Published online: 30 January 2019

(C) The Chinese Society for Metals and Springer-Verlag GmbH Germany, part of Springer Nature 2019

\begin{abstract}
The effect of simulated acidified marine aerosols on the corrosion morphology of carbon steel was studied using an in situ optical stereomicroscope and scanning electron microscope equipped with an energy-dispersive spectrometer and a whitelight interferometer. The morphologies of the carbon steel were identified under marine aerosols with different droplet diameters, $\mathrm{pH}$, and acidifications. The results showed that corrosion was initiated in tens of seconds under aerosol droplets acidified by $\mathrm{HCl}$ or $\mathrm{H}_{2} \mathrm{SO}_{4}$. Despite the differences in the acidifier and diameter, corrosion for acidified droplets with $\mathrm{pH}>2$ was general corrosion. For acidified droplets with $\mathrm{pH}<1$, the corrosion morphology depended on the acidifier species, the ring-like morphology for $\mathrm{HCl}$ and ridge-like morphology for $\mathrm{H}_{2} \mathrm{SO}_{4}$. The segregation of $\mathrm{Cl}^{-}$was believed to be the main factor for the formation of the corrosion morphology under acidified droplets with $\mathrm{pH}<1$. Also, the concentration of $\mathrm{SO}_{4}{ }^{2-}$ in the droplets had some effect on the segregation of $\mathrm{Cl}^{-}$ions when $\mathrm{pH}<1$.
\end{abstract}

Keywords Atmospheric corrosion · Aerosol · Acidification $\cdot$ Carbon steel $\cdot \mathrm{pH} \cdot$ Corrosion morphology

\section{Introduction}

Atmospheric corrosion is inevitable when materials are exposed to ambient air. Because the economic loss caused by atmospheric corrosion accounts for half of that caused by corrosion every year, many researches have been done in this domain [1-7]. Aerosols are environmental products that generally suspend in the air and can absorb various species of contaminants, such as chlorides and sulfur dioxide [8]. Because oxide dissolution and high corrosion rates of metals can be caused by the high dissolved ion contents, low $\mathrm{pH}$, and micro size of aerosols [8-11], atmospheric corrosion

Available online at http://link.springer.com/journal/40195

Chuan Wang

cwang@imr.ac.cn

Zhen-Yao Wang

zhywang@imr.ac.cn

1 Environment Corrosion Center, Institute of Metal Research, Chinese Academy of Sciences, Shenyang 110016, China

2 University of Chinese Academy of Sciences, Beijing 100049, China

3 School of Materials Science and Engineering, University of Science and Technology of China, Hefei 230026, China induced by aerosols has received much more attention in recent decades, especially in marine environments [12-19].

The size of the aerosols affects the constitution of aerosols, deposition efficiency, diffusion of $\mathrm{O}_{2}$, and distribution of cathode and anode under aerosol droplets [8, 20,21]; thus, its effect on the corrosion behavior has been investigated in many works [20, 22-25]. It is reported that there are critical diameters for the aerosols to induce corrosion of carbon steel [22-25]. For example, Li et al. [22, 26] found that the critical diameter was approximately $45 \mu \mathrm{m}$ for 1018 steel and 150-200 $\mu \mathrm{m}$ for ultrapure iron. When the diameters of the droplets were smaller than the critical values, corrosion was not observed. In addition, two types of corrosion were observed depending on the size: filiform-type corrosion for small droplets and Evan-type corrosion for large droplets [22, 23, 27-31]. For filiform corrosion, a model proposed by Weissenrieder and Leygraf [29] attributed the formation of filaments to the transport of $\mathrm{Cl}^{-}$. They concentrated in the head of filament, differential aeration cell, and the successive formation of a new anode and cathode.

Most previous studies have focused on the effect of aerosol size on the corrosion behavior for carbon steel. However, aerosols absorb and react with many kinds of pollutant gas, such as $\mathrm{SO}_{2}, \mathrm{NO}_{x}, \mathrm{NH}_{3}$, and $\mathrm{HCl}$, during the transportation process, which can change the composition of aerosols 
significantly, especially the $\mathrm{pH}$ of aerosols [8, 32]; for example, the typical $\mathrm{pH}$ for the acidified aerosols ranges from 1 to $4[8,13]$. Hence, it is necessary to clarify the effects of aerosol $\mathrm{pH}$ and acidifier species on the corrosion process for carbon steel.

In contrast, the effect of various simulated acidified aerosol droplets on the corrosion of $\mathrm{Zn}$ has been studied [3, $8,12,13,33]$. The results show that the corrosion rate is related to the chloride concentration and the acidification type. The difference of corrosion rates under the droplets with different acidification types became apparent only in the presence of a relatively higher concentration of chloride. Interestingly, the corrosion of $\mathrm{Zn}$ under sulfur-containing aerosol droplets exhibited a lower corrosion rate, which can be attributed to the formation of zinc and sulfur complexes. In addition, the secondary spreading effect can be notably inhibited in an environment containing $\mathrm{SO}_{2}$ because of the acidification of aerosol droplets.

Although the corrosion of carbon steel under acidified aerosols has not been studied, the corrosion of carbon steel under a liquid film was studied in the simulated atmosphere containing $\mathrm{SO}_{2}$. For the corrosion of carbon steel, sulfate nests were observed in an environment containing $\mathrm{SO}_{2}[1$, $4,34]$. In the corrosion process, $\mathrm{SO}_{2}$ penetrated the ruptured corrosion products film, leading to the formation of sulfate nests. However, there is an inherent difference between the aerosols and thin film, so the effects of $\mathrm{SO}_{4}{ }^{2-}$ and $\mathrm{pH}$ on the aerosol corrosion are not clear. Further work needs to be done to investigate the corrosion behavior of carbon steel under acidified aerosols.

The aim of this work is to clarify the effects of aerosol acidification type, $\mathrm{pH}$, and diameter on the corrosion of Q235 carbon steel. The corrosion morphology was observed by in situ stereomicroscopy and ex situ scanning electron microscopy (SEM). The element distribution was obtained by an energy-dispersive spectrometer (EDS). Ultimately, this work can contribute to a better understanding of the effect of acidified aerosols on the corrosion morphology of carbon steel and the synergistic effect of ion species under the droplets during atmospheric corrosion.

\section{Experimental}

\subsection{Material}

The samples used in this work were Q235 carbon steel with a size of $10 \mathrm{~mm} \times 10 \mathrm{~mm} \times 3 \mathrm{~mm}$. The composition of Q235 carbon steel was examined by inductively coupled plasma emission spectrometer (ThermoFisher ICAP6300, USA), and the result is shown in Table 1. The samples were mechanically ground with $400 \#, 800 \#, 2000 \# \mathrm{SiC}$ paper successively and then polished with $2.5 \mu \mathrm{m}$ diamond paste. Finally, the samples were rinsed with deionized water and ethanol and dried by cold flowing air. The samples were stored in a desiccator $(<10 \% \mathrm{RH})$ for at least $2 \mathrm{~d}$ before the experiment.

\subsection{Solution Preparation and Aerosol Deposition}

The base solution used in the experiment was $3.5 \% \mathrm{NaCl}$ solution. To explore the effect of acidification, $\mathrm{NaCl}$ solutions were acidified by $\mathrm{HCl}$ and $\mathrm{H}_{2} \mathrm{SO}_{4}$, respectively, and the $\mathrm{pH}$ values were set as 1,2, and 3 for each acidified type of solution. For the solution acidified by $\mathrm{H}_{2} \mathrm{SO}_{4}$, two acidifying methods were used. The first method was that the aerosols were acidified directly by $\mathrm{H}_{2} \mathrm{SO}_{4}$; the second one was the aerosols were acidified by $\mathrm{Na}_{2} \mathrm{SO}_{4}$ and $\mathrm{HCl}$, so that $\mathrm{pH}$ (or the concentration of $\mathrm{SO}_{4}{ }^{2-}$ ) remained unchanged when changing the concentration of $\mathrm{SO}_{4}{ }^{2-}($ or $\mathrm{pH})$. For all the acidified solutions, the concentration of $\mathrm{Cl}^{-}$was $0.6 \mathrm{~mol} / \mathrm{L}$, and $3.5 \% \mathrm{NaCl}$ solutions that were not acidified served as a comparison. The solution used in the experiment is shown in Table 2.
Table 1 Chemical compositions of Q235 (wt \%)

Table 2 Solution used in the experiment with different $\mathrm{pH}$ and concentrations of $\mathrm{SO}_{4}{ }^{2-}$ $\left(C_{\mathrm{Cl}^{-}}\right.$: concentration of $\mathrm{Cl}^{-}$; $C_{\mathrm{SO}_{4}^{2-}}$ concentration of $\mathrm{SO}_{4}{ }^{2-}$ )

\begin{tabular}{lllllll}
\hline Steel & C & Si & Mn & P & S & Fe \\
\hline Q235 & 0.14 & 0.01 & 0.33 & 0.011 & 0.02 & Bal. \\
\hline
\end{tabular}

\begin{tabular}{lllll}
\hline Base solution & Acidifier & $C_{\mathrm{Cl}^{-}}(\mathrm{mol} / \mathrm{L})$ & $\mathrm{pH}$ & $C_{\mathrm{SO}_{4}^{2-}}(\mathrm{mol} / \mathrm{L})$ \\
\hline $\mathrm{NaCl}$ & - & 0.6 & $5.5-6.0$ & - \\
$\mathrm{NaCl}$ & $\mathrm{HCl}$ & 0.6 & $1 / 2 / 3$ & - \\
$\mathrm{NaCl}$ & $\mathrm{H}_{2} \mathrm{SO}_{4}$ & 0.6 & $1 / 2 / 3$ & $5 \times 10^{-2} / 5 \times 10^{-3} / 5 \times 10^{-4}$ \\
$\mathrm{NaCl}$ & $\mathrm{Na}_{2} \mathrm{SO}_{4}+\mathrm{HCl}$ & 0.6 & $1 / 2 / 3$ & $5 \times 10^{-2} / 5 \times 10^{-3} / 5 \times 10^{-4}$ \\
$\mathrm{NaCl}$ & $\mathrm{Na}_{2} \mathrm{SO}_{4}+\mathrm{HCl}$ & 0.6 & 1 & $5 \times 10^{-2} / 5 \times 10^{-3} / 5 \times 10^{-4}$ \\
$\mathrm{NaCl}$ & $\mathrm{Na}_{2} \mathrm{SO}_{4}+\mathrm{HCl}$ & 0.6 & 2 & $5 \times 10^{-2}, 0.6$ \\
$\mathrm{NaCl}$ & $\mathrm{Na}_{2} \mathrm{SO}_{4}+\mathrm{HCl}$ & 0.6 & 3 & $5 \times 10^{-2}, 0.6$ \\
\hline
\end{tabular}


The aerosol droplets were deposited on the surface of samples by a sprayer, and the diameters ranged from 50 to $250 \mu \mathrm{m}$. After deposition, the samples were immediately put in a humidity chamber with $90 \pm 3 \% \mathrm{RH}$. The experiments with different solutions were repeated for three times at least.

\subsection{Observation of Corrosion Morphology and Measurement of Size of Corrosion Pits}

The corrosion morphology was observed using an XL30PHILIPS SEM at $25 \mathrm{kV}$ after corrosion for $6 \mathrm{~h}$. The chemical composition of the corrosion products and the distribution of different elements were analyzed by EDS (Oxford Instruments).

Corrosion products formed on the surface of carbon steel after corrosion for $6 \mathrm{~h}$ were removed by immersing the samples in the derusting solution (mixture of $3.5 \mathrm{~g}$ of hexamethylenetetramine, $500 \mathrm{~mL}$ of $38 \%$ hydrochloric acid, and $500 \mathrm{~mL}$ of deionized water) for $10 \mathrm{~min}$ according to ISO 8407. Then, the samples were rinsed with deionized water and alcohol, dried with cold flowing air, and stored in desiccator. The size of the corrosion pits was measured by a MicroXAM white-light interferometer.

A schematic diagram of the in situ observation experimental setup is shown in Fig. 1. The microscopic images were taken through the hole in the upper face covered by a thin (the thickness is $\sim 0.15 \mathrm{~mm}$ ) glass. A glycerol-water solution was placed at the bottom of the humidity chamber to keep $90 \pm 3 \%$ RH. Samples were put in the humidity chamber immediately after aerosol droplets were deposited on the surface of the samples. The morphologies of the corrosion products were taken by an in situ stereomicroscope. The temperature set in the experiment was $25 \pm 3{ }^{\circ} \mathrm{C}$.

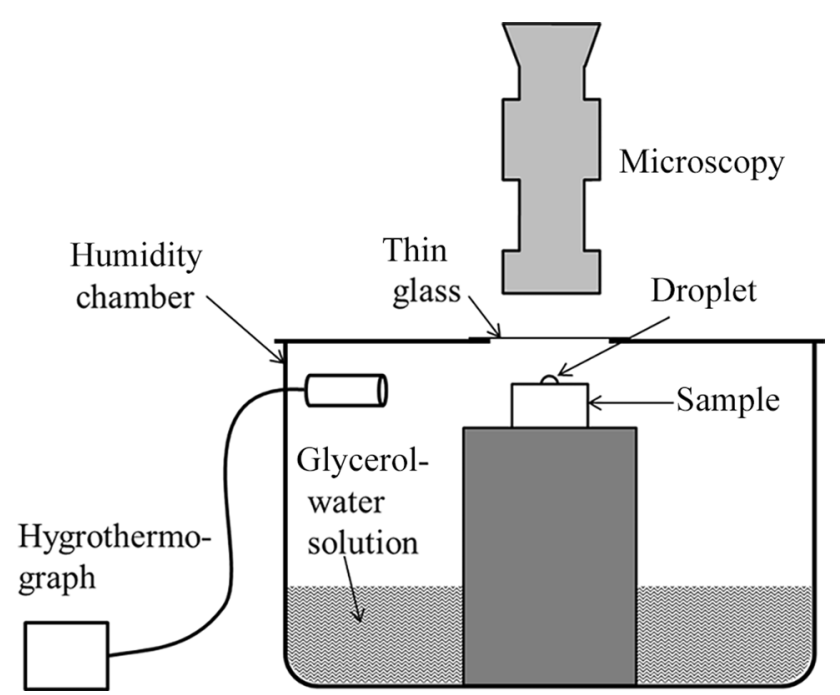

Fig. 1 Schematic diagram of in situ observation experimental setup

\section{Results and Discussion}

\subsection{Corrosion Morphology Under Different Acidified Droplets}

The corrosion morphology under acidified droplets for $6 \mathrm{~h}$ in a humidity chamber was studied by SEM. The corrosion morphologies under droplets acidified by $\mathrm{HCl}$ to different $\mathrm{pH}$ are shown in Fig. 2. The corrosion type under not-acidified $\mathrm{NaCl}$ droplets was filiform corrosion for the droplet size ranging from 50 to $250 \mu \mathrm{m}$ (Fig. 2d), and the result was consistent with previous reports $[22,23]$. The main feature of filiform corrosion is that the filament extended from the edge of the droplet to surrounding areas, and the growth of the filament was irregular [29, 30]. When the $\mathrm{NaCl}$ droplets were acidified by $\mathrm{HCl}$ with $\mathrm{pH}=2$ and $\mathrm{pH}=3$, corrosion was generally confined to the area that the initial droplets covered. For these droplets, the distribution of the corrosion products was uniform, and only local areas had more corrosion products than other areas (Fig. 2b, c). However, for the droplets acidified by $\mathrm{HCl}$ with $\mathrm{pH}=1$ (Fig. 2a), the corrosion morphology was much different. Ring-like morphology was observed, which meant that more corrosion products were deposited on the periphery of droplets, and fewer corrosion products were deposited in the center of the droplet. Furthermore, one or several points with more corrosion products were observed at the corrosion product ring. Also, corrosion was confined to the initial droplet area.

When the droplets were acidified by $\mathrm{H}_{2} \mathrm{SO}_{4}$ (Fig. 3), the corrosion morphology exhibited the same regularity as the droplets were acidified by $\mathrm{HCl}$. For the $\mathrm{NaCl}$ droplets acidified by $\mathrm{H}_{2} \mathrm{SO}_{4}$ with $\mathrm{pH}=2$ and $\mathrm{pH}=3$ (Fig. 3b, c), the corrosion products were deposited under the droplets uniformly, just as the droplets were acidified by $\mathrm{HCl}$. When the $\mathrm{pH}$ of the acidified droplets was set as 1 , the corrosion morphology was ridge like, which was characterized by radial raised corrosion product morphology in the periphery of the droplets and irregularly raised ring-like corrosion product morphology at the end of the raised radial products. Likewise, one or several severe corrosion points with more corrosion products were observed on the raised radial or ring-like products area (Fig. 3a).

In the case of droplets acidified by $\mathrm{H}_{2} \mathrm{SO}_{4}$, the change in $\mathrm{pH}$ was accompanied by the change in the concentration of $\mathrm{SO}_{4}{ }^{2-}$. Therefore, to explore the effects of $\mathrm{pH}$ and concentration of $\mathrm{SO}_{4}{ }^{2-}$ on corrosion morphology, respectively, the droplets were acidified by $\mathrm{Na}_{2} \mathrm{SO}_{4}$ and $\mathrm{HCl}$ instead of $\mathrm{H}_{2} \mathrm{SO}_{4}$ only. When the concentration of $\mathrm{SO}_{4}{ }^{2-}$ was set as $0.05 \mathrm{~mol} / \mathrm{L}$ and $0.6 \mathrm{~mol} / \mathrm{L}$, the corrosion morphology varying with different $\mathrm{pH}$ exhibited the same change rule (Figs. 4,5 ) as the droplets were acidified by 

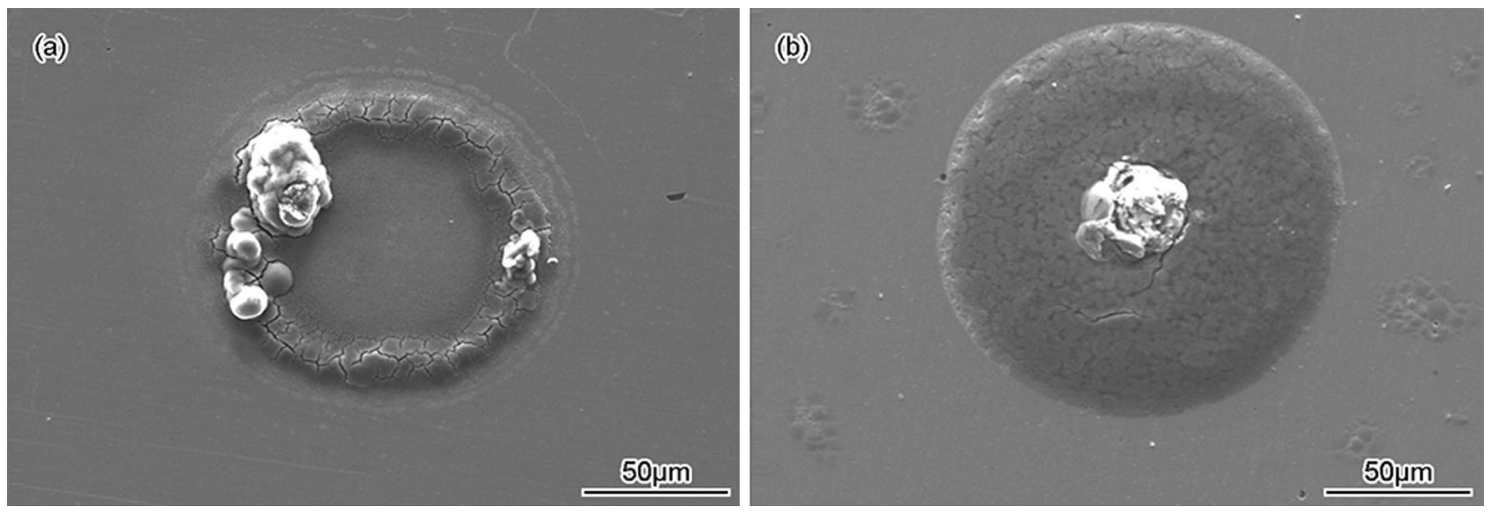

(c)

\section{(d)}
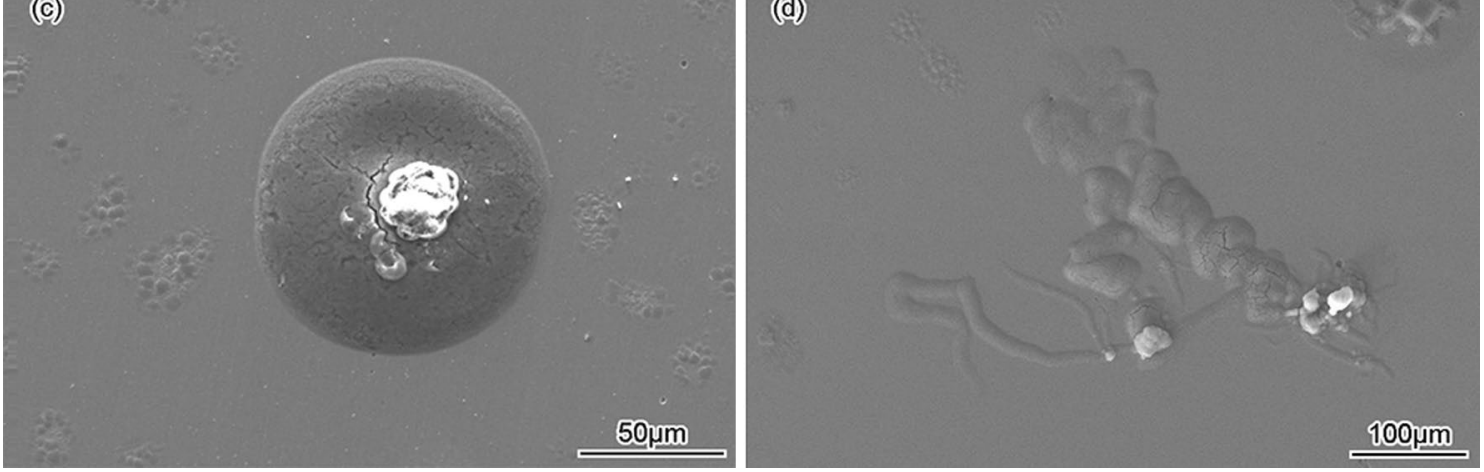

Fig. 2 Morphologies of corrosion products under droplets acidified by $\mathrm{HCl}$ with: $\mathbf{a} \mathrm{pH}=1 ; \mathbf{b} \mathrm{pH}=2 ; \mathbf{c} \mathrm{pH}=3$; $\mathbf{d} \mathrm{pH}=5-6$ (not acidified)
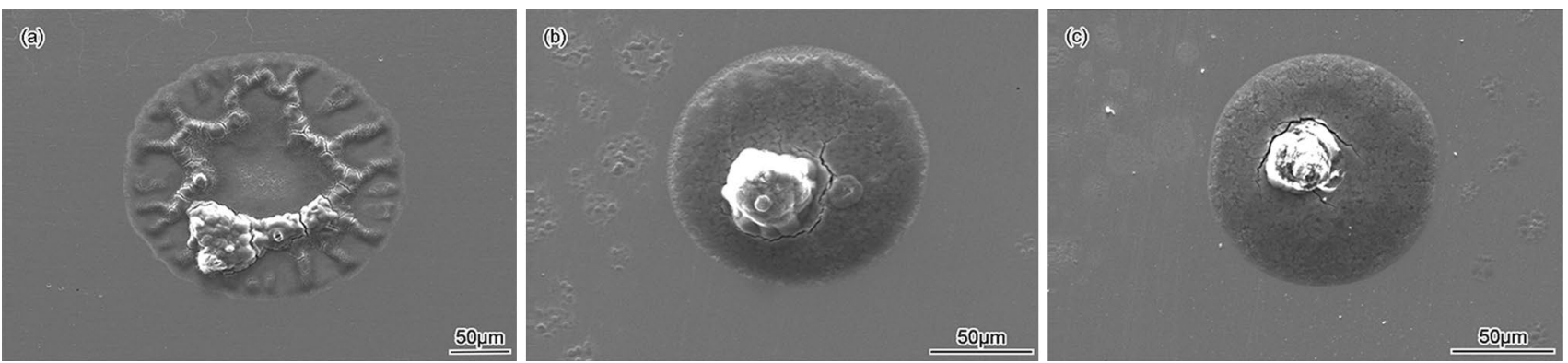

Fig. 3 Morphologies of corrosion products under droplets acidified by $\mathrm{H}_{2} \mathrm{SO}_{4}$ with: $\mathbf{a} \mathrm{pH}=1 ; \mathbf{b} \mathrm{pH}=2 ; \mathbf{c} \mathrm{pH}=3$
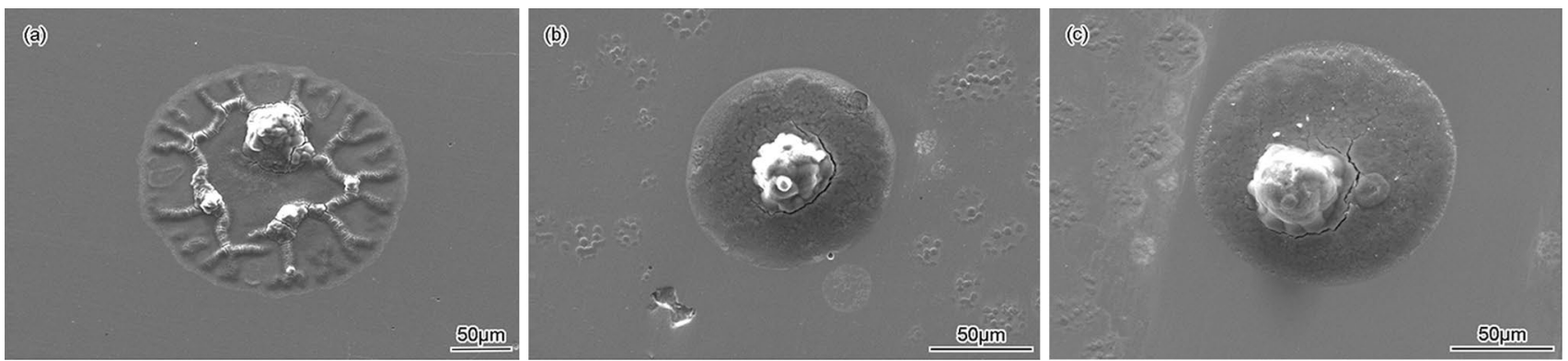

Fig. 4 Effects of $\mathrm{pH}$ on morphologies of corrosion products under droplets with $0.05 \mathrm{~mol} / \mathrm{L} \mathrm{SO}_{4}{ }^{2-}: \mathbf{a} \mathrm{pH}=1 ; \mathbf{b} \mathrm{pH}=2 ; \mathbf{c} \mathrm{pH}=3$ 

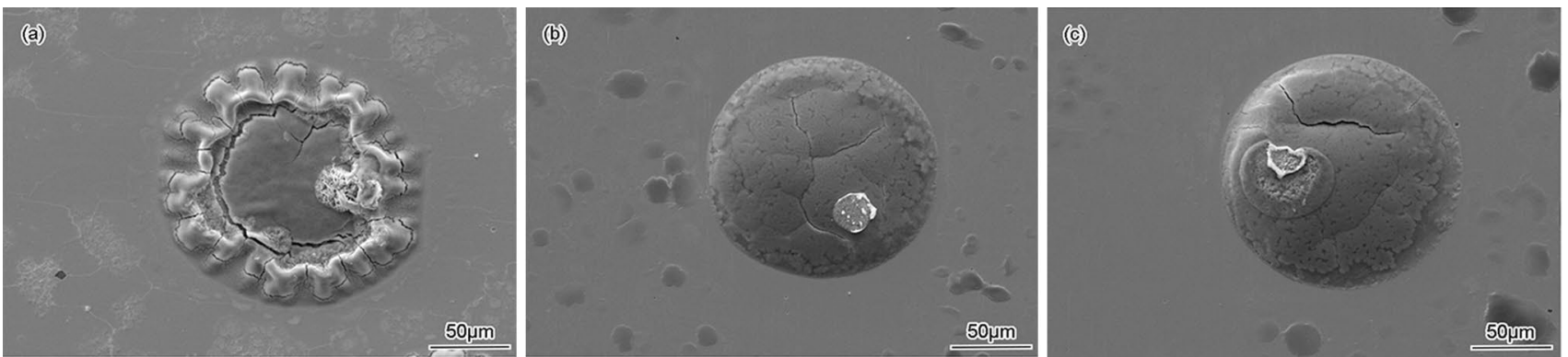

Fig. 5 Effects of $\mathrm{pH}$ on morphologies of corrosion products under droplets with $0.6 \mathrm{~mol} / \mathrm{L} \mathrm{SO}_{4}{ }^{2-}: \mathbf{a} \mathrm{pH}=1 ; \mathbf{b} \mathrm{pH}=2 ; \mathbf{c} \mathrm{pH}=3$

$\mathrm{H}_{2} \mathrm{SO}_{4}$ directly. When $\mathrm{pH}$ was set as 1 , the effect of concentration of $\mathrm{SO}_{4}{ }^{2-}$ on corrosion morphology was investigated (Fig. 6). The concentrations of $\mathrm{SO}_{4}{ }^{2-}$ were set the same as the droplets were acidified by $\mathrm{H}_{2} \mathrm{SO}_{4}$ directly with $\mathrm{pH}=1,2$ and 3 (Fig. 3), respectively. Figure 6 shows that a ring-like morphology instead of ridge-like morphology was observed when the concentration of $\mathrm{SO}_{4}{ }^{2-}$ was low relatively.

Overall, in spite of the difference in acidifiers and diameters, corrosion morphologies for acidified droplets with $\mathrm{pH}>2$ were similar, and corrosion products were deposited under the droplets uniformly. However, for acidified droplets with $\mathrm{pH}<1$, corrosion morphology depended on the acidification-a ring-like morphology for $\mathrm{HCl}$ acidified and ridge-like morphology for $\mathrm{H}_{2} \mathrm{SO}_{4}$ acidified. When the concentration of $\mathrm{SO}_{4}{ }^{2-}$ was relatively low for aerosols with $\mathrm{pH}=1$, the corrosion morphology transformed into a ring-like morphology.

After the removal of corrosion products, the size of the corrosion pits was measured using a white-light interferometer, and the result is shown in Fig. 7. The depth of the corrosion pits corresponds to the corrosion morphology. The more the corrosion products in the area deposited, the deeper the corrosion pits were, and the more severely corroded the area.

\subsection{In Situ Observation of Initial Corrosion}

For the acidified droplets, the corrosion morphology changed greatly with different $\mathrm{pH}$ and acidified solution type. Thus, it was necessary to learn about the formation process of the corrosion morphology for better understanding the corrosion mechanism under acidified droplets. The aerosol droplets acidified by $\mathrm{H}_{2} \mathrm{SO}_{4}$ with $\mathrm{pH}=1$ showed a special morphology; thus, in situ observation of corrosion under the acidified droplet was studied by a stereomicroscope (Figs. 8, 9).

The corrosion morphology under the droplets acidified by $\mathrm{H}_{2} \mathrm{SO}_{4}$ with $\mathrm{pH}=1$ was a ridge-like morphology (Fig. 3a), and initial corrosion morphologies varying with time are shown in Fig. 8. Three droplets with different sizes were observed in the sights. After corrosion for $30 \mathrm{~s}$, radial products appeared on the periphery of the largest droplet, continued to grow toward the center of the droplet, and then stopped growing after a few minutes. In the following process, an irregularity ring formed at the front end of the radial products.

Once formed in the initial corrosion stage, the ridgelike morphology kept unchanged, and no new raised structures formed under the droplets in the following corrosion process (seen in Fig. 9). The local area becomes rust red, which may be the color of the bare corrosion product;
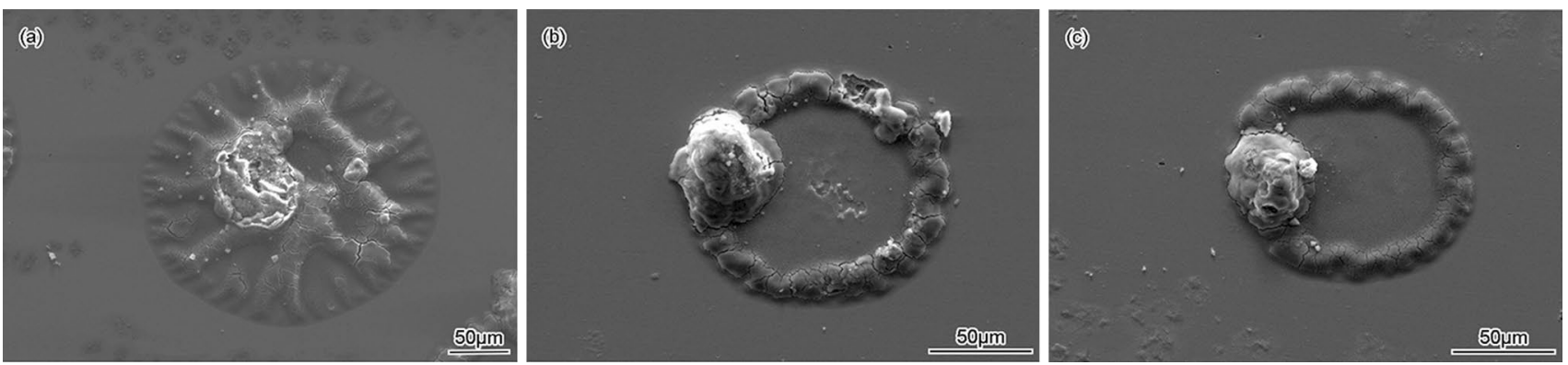

Fig. 6 Effects of $\mathrm{SO}_{4}{ }^{2-}$ concentration on morphologies of corrosion products under droplets with $\mathrm{pH}=1: \mathbf{a ~} 0.05 \mathrm{~mol} / \mathrm{L}$; b $0.005 \mathrm{~mol} / \mathrm{L}$; c $0.0005 \mathrm{~mol} / \mathrm{L}$ 

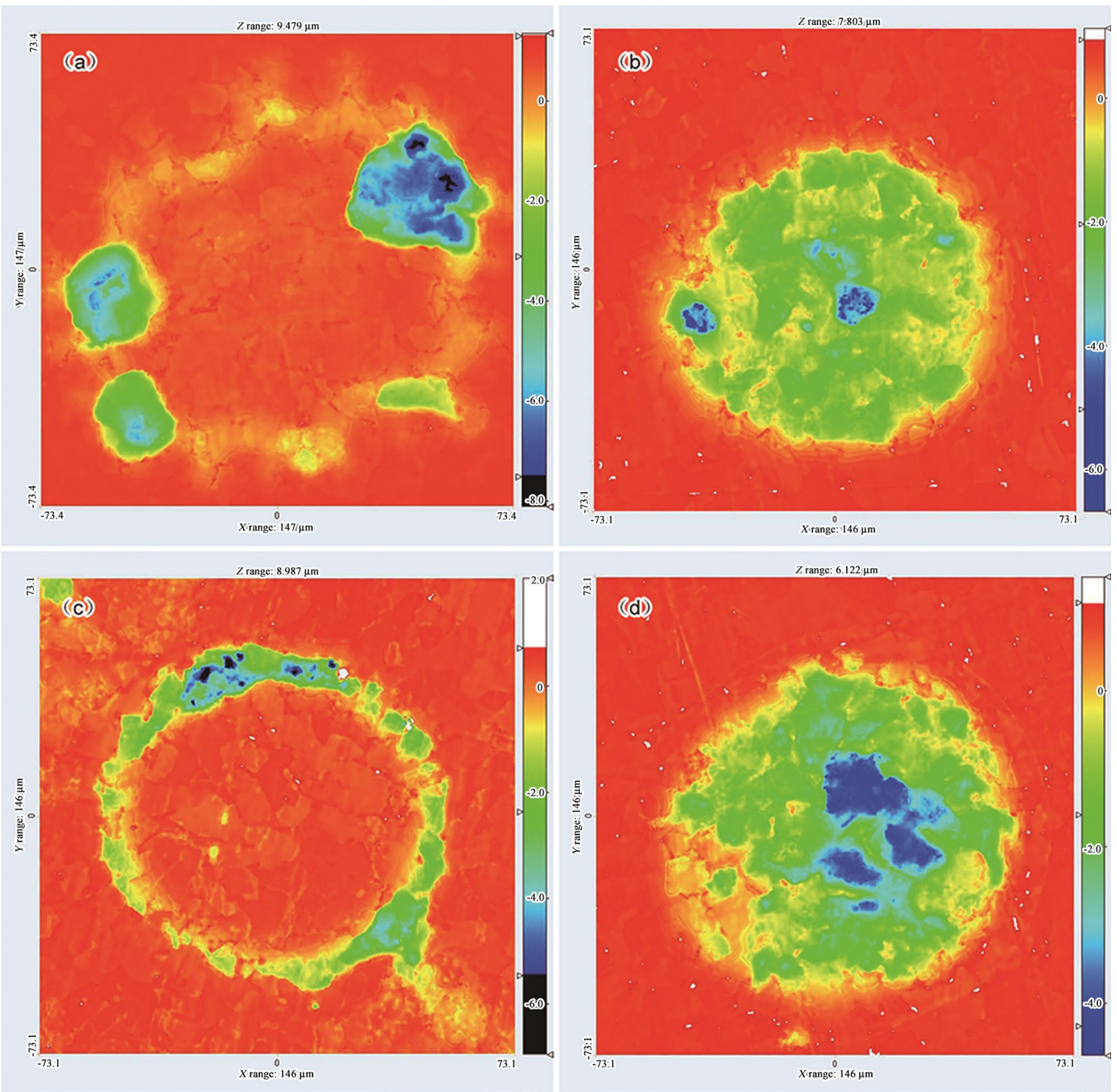

Fig. 7 Morphologies of corrosion pits after removal of corrosion products under droplets: a acidified by $\mathrm{H}_{2} \mathrm{SO}_{4}$ with $\mathrm{pH}=1$; $\mathbf{b}$ acidified by $\mathrm{H}_{2} \mathrm{SO}_{4}$ with $\mathrm{pH}=2$; $\mathbf{c}$ acidified by $\mathrm{HCl}$ with $\mathrm{pH}=1 ; \boldsymbol{d}$ acidified by $\mathrm{HCl}$ with $\mathrm{pH}=2$

this can due to the evaporation of water after tens of minutes. One more thing that should be noted was the order in which the rust red appeared. The periphery of the droplet became rust red first, and then the center. The water did not disappear on the raised corrosion products until corrosion for $5 \mathrm{~h}$, which was attributed to the high hygroscopicity of the corrosion products. The corrosion morphology under small droplets showed a similar formation process to that of the largest droplet.
Furthermore, the rate of formation of the ridge-like morphology depended on the size of the droplets, and small droplets showed a faster rate of formation. Additionally, the length of raised radial products was relatively shorter for small droplets. After corrosion for several hours, one or several severe corrosion points formed on the area of raised corrosion products. 

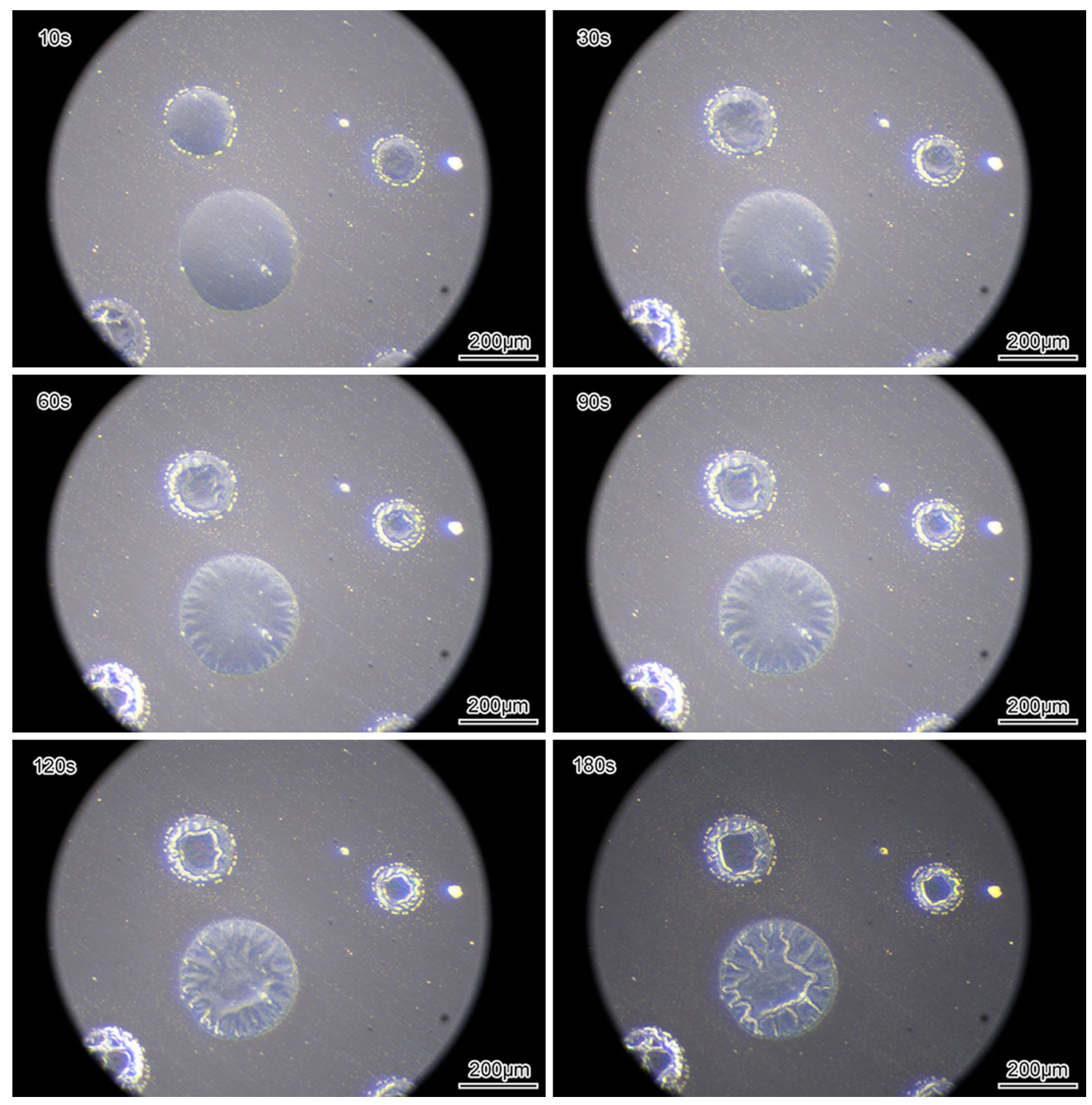

Fig. 8 Initial corrosion morphologies varied with time under droplets acidified by $\mathrm{H}_{2} \mathrm{SO}_{4}$ with $\mathrm{pH}=1$

The formation of corrosion morphology for droplets acidified by $\mathrm{HCl}$ with $\mathrm{pH}=1$ was similar to that of droplets acidified by $\mathrm{H}_{2} \mathrm{SO}_{4}$ with $\mathrm{pH}=1$, so it is not shown here.

\subsection{Element Distribution of Corrosion Products}

To better understand the corrosion mechanism, the element distribution of corrosion products under droplets acidified by $\mathrm{H}_{2} \mathrm{SO}_{4}$ with $\mathrm{pH}=1$ was studied. The EDS mapping of the corrosion products after corrosion for $30 \mathrm{~min}$ is shown in Fig. 10, and the results showed that the chlorine and oxygen mostly concentrated on the area of raised corrosion products. The content of $\mathrm{SO}_{4}{ }^{2-}$ was so low that the variation of content on the element area profile was not apparent under the droplet. Therefore, the element compositions of different points under droplets acidified by $\mathrm{H}_{2} \mathrm{SO}_{4}$ with $\mathrm{pH}=1$ were analyzed after corrosion for $6 \mathrm{~h}$ (Fig. 11). Only a small amount of element $\mathrm{S}$ was detected on the severe corrosion point, whereas on the other raised corrosion products, element $S$ was not detected.

For the corrosion under droplets acidified by $\mathrm{HCl}$ with $\mathrm{pH}=1$, the element $\mathrm{Cl}$ also concentrated on the raised ringlike corrosion products. Furthermore, the content of element $\mathrm{Cl}$ on the severe corrosion point was higher than that of other raised corrosion products (Fig. 11).

\subsection{Corrosion Mechanism}

The corrosion of carbon steel under $\mathrm{NaCl}$ aerosol droplets was studied in the previous work, and the formation 

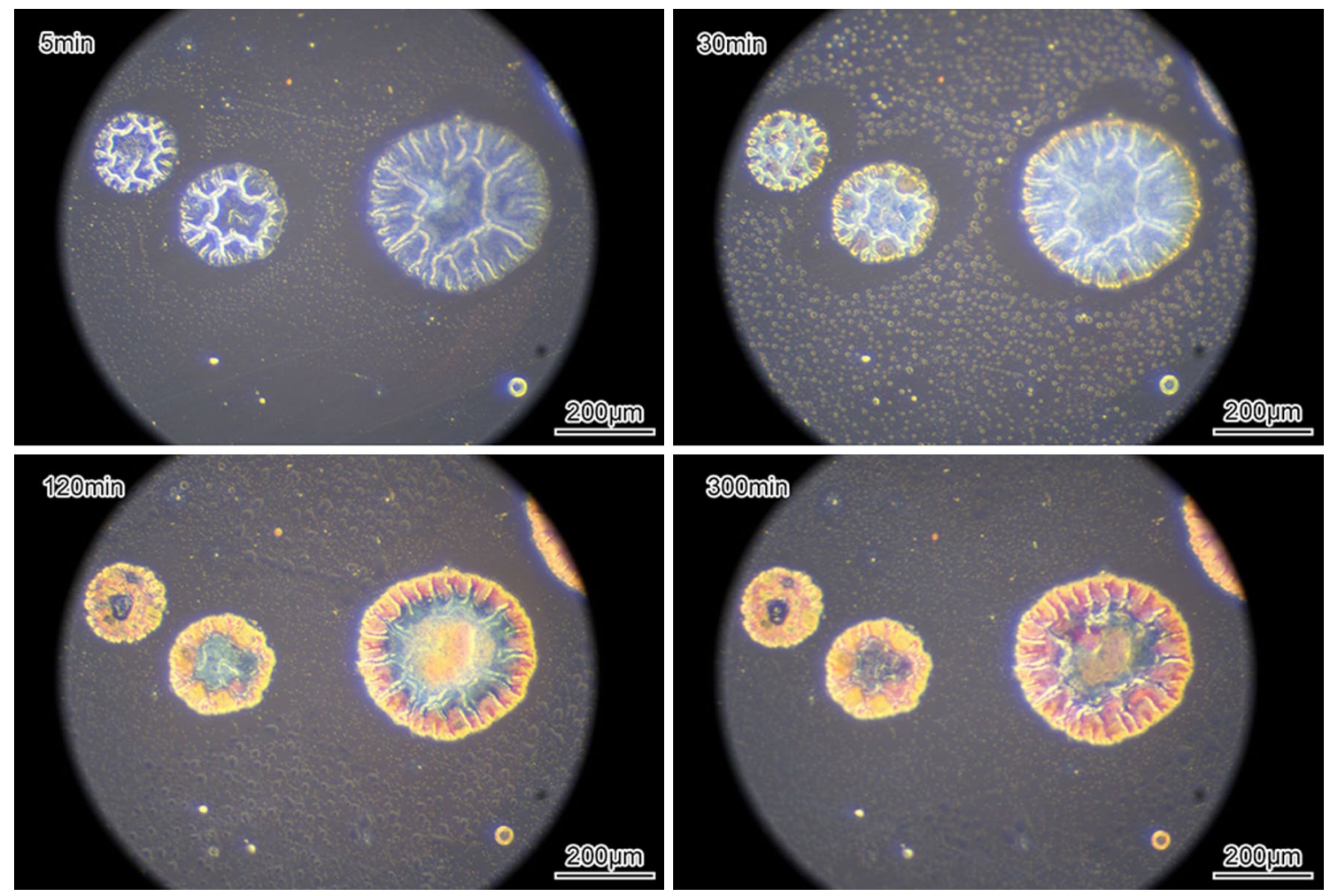

Fig. 9 Corrosion morphologies varied with time under droplets acidified by $\mathrm{H}_{2} \mathrm{SO}_{4}$ with $\mathrm{pH}=1$

mechanism of the filiform corrosion and Evan-type corrosion on the iron surface caused by $\mathrm{NaCl}$ droplets was proposed [23, 29]. However, the acidified $\mathrm{NaCl}$ aerosol droplets exhibited great variation in the corrosion morphology; thus, it is necessary to propose a new corrosion mechanism.

For Evan-type corrosion under the $\mathrm{NaCl}$ droplets, the distribution of anode and cathode is decided by the differentiation of oxygen concentration, and the periphery of the droplets acts as the cathode because of higher oxygen concentration [28]. However, for acidified $\mathrm{NaCl}$ droplets, the main cathodic reaction is the hydrogen evolution as follows:

$2 \mathrm{H}^{+}+2 \mathrm{e}^{-} \rightarrow \mathrm{H}_{2}$.

Hence, the distribution of anode and cathode is related to the microstructure, such as the second phase and impurities. When the acidified $\mathrm{NaCl}$ aerosol droplets were deposited on the surface of carbon steel, the oxidation film on the surface was dissolved first, and the concentration of $\mathrm{H}^{+}$then decreased. The periphery of the droplets was relatively thin and contained more oxygen because of shorter diffuse distance. For the periphery of the droplets, the proportion of the oxygen reduction reaction as the cathodic reaction increased with the decrease of $\mathrm{H}^{+}$. As the reaction progressed, the main cathodic reaction became the oxygen reduction reaction, and the concentration of $\mathrm{OH}^{-}$increased gradually. While the center of the droplets had lower concentration of oxygen, the proportion of oxygen reduction reaction is lower compared with the periphery and so was the $\mathrm{pH}$ value. Hence, the distribution of cathode and anode changed with the corrosion time, and the periphery of the droplet served as the cathode and the center of the droplet as the anode. The separation of cathode and anode under droplets led to the migration of ions. The cations (anions) under droplets migrate toward the cathode (anode) (Fig. 12a). The reactions that occurred under the droplets are shown below:

$\mathrm{O}_{2}+4 \mathrm{e}^{-}+2 \mathrm{H}_{2} \mathrm{O} \rightarrow 4 \mathrm{OH}^{-}$,

$\mathrm{Fe} \rightarrow \mathrm{Fe}^{n+}+n \mathrm{e}^{-}$.

When the $\mathrm{NaCl}$ droplets were acidified, the acidic environment under the droplet was against the deposition of the corrosion product in the initial corrosion stage. For the $\mathrm{NaCl}$ droplets acidified by $\mathrm{HCl}$ with $\mathrm{pH}=2$ and 3 , with increasing corrosion time, the $\mathrm{pH}$ of both the center and the perimeter of the droplet increased quickly, which benefited the deposition of the corrosion product. Therefore, there was no great difference for the amount of deposited corrosion product between the center and perimeter because of the quick change of $\mathrm{pH}$. Therefore, the corrosion morphology under the $\mathrm{NaCl}$ droplets acidified by $\mathrm{HCl}$ with $\mathrm{pH}=2$ and 3 was uniform corrosion. Also, because of the inhomogeneous 

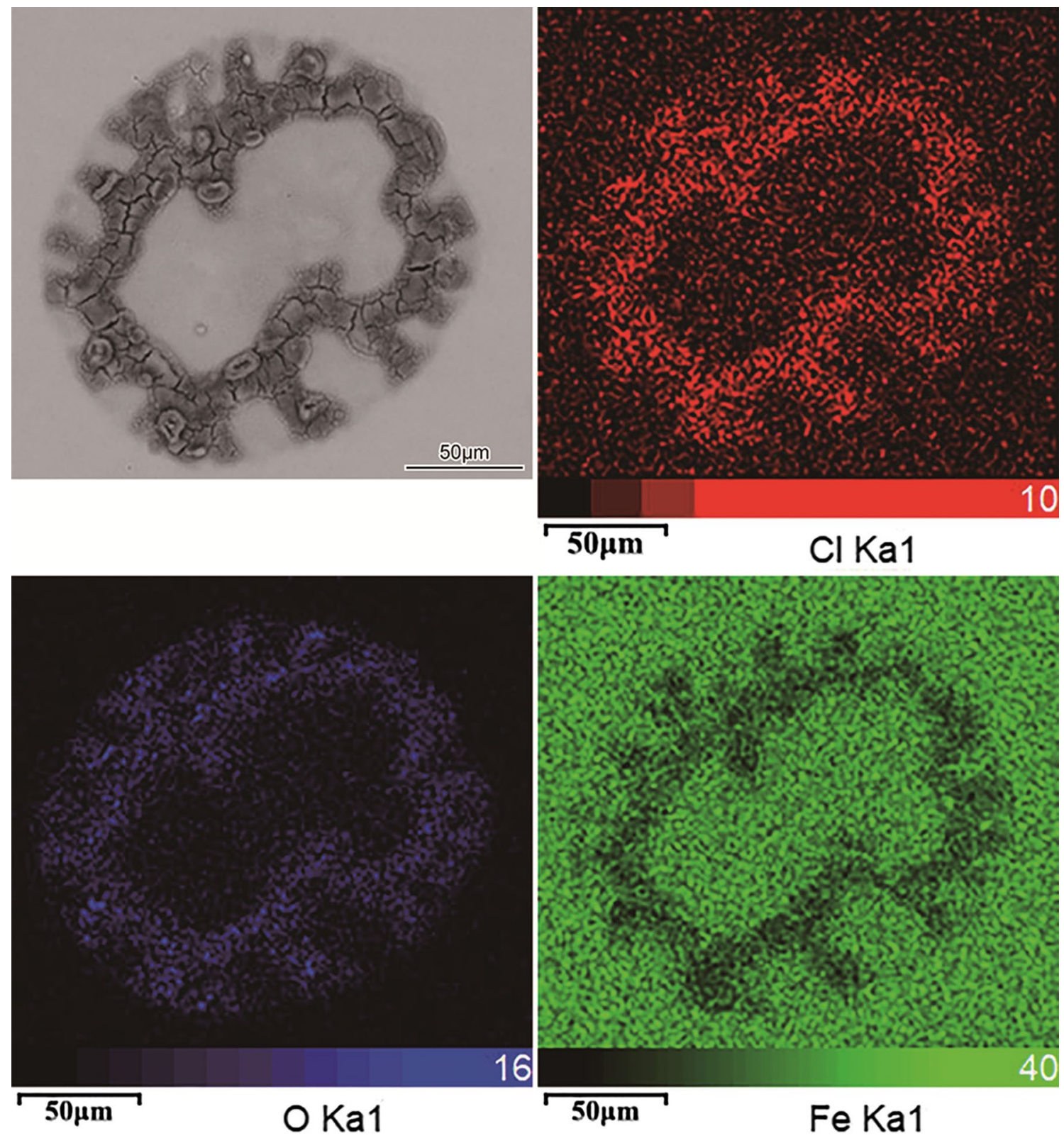

$50 \mu \mathrm{m}$

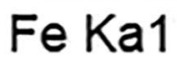

Fig. 10 EDS mapping of corrosion products under droplet acidified by $\mathrm{H}_{2} \mathrm{SO}_{4}$ with $\mathrm{pH}=1$ for 30 min

nature of the corrosion products deposited under the droplets, the local area acted as the anode, and $\mathrm{Cl}^{-}$migrated toward the anode, leading to a higher content of $\mathrm{Cl}^{-}$than that in the perimeter area. After a certain corrosion time, the high ion concentration led to a local area corroded more severely than the other area (Fig. 2b, c).

However, for the $\mathrm{NaCl}$ droplets acidified by $\mathrm{HCl}$ with $\mathrm{pH}=1$, the concentration of $\mathrm{H}^{+}$was relatively high, and it took more time for increasing $\mathrm{pH}$ to make the environment beneficial to the deposition of corrosion products, especially for the center of the droplets. This means that much more time is necessary for the corrosion products to be deposited on the center of the droplet when the corrosion products began to be deposited on the periphery of the droplet. Therefore, the corrosion products were deposited on the perimeter of the droplet first, and the amount of the corrosion products was much more than at the center of the droplet in the early stage. Because the corrosion product was formed by deposition, it should be porous [29]. Thus, they will absorb more water from the adjacent area. As a result, with increasing corrosion time, more water and $\mathrm{Cl}^{-}$were concentrated on the periphery of the droplet with more corrosion products, which led to the periphery acting as the anode and being corroded more severely than the 


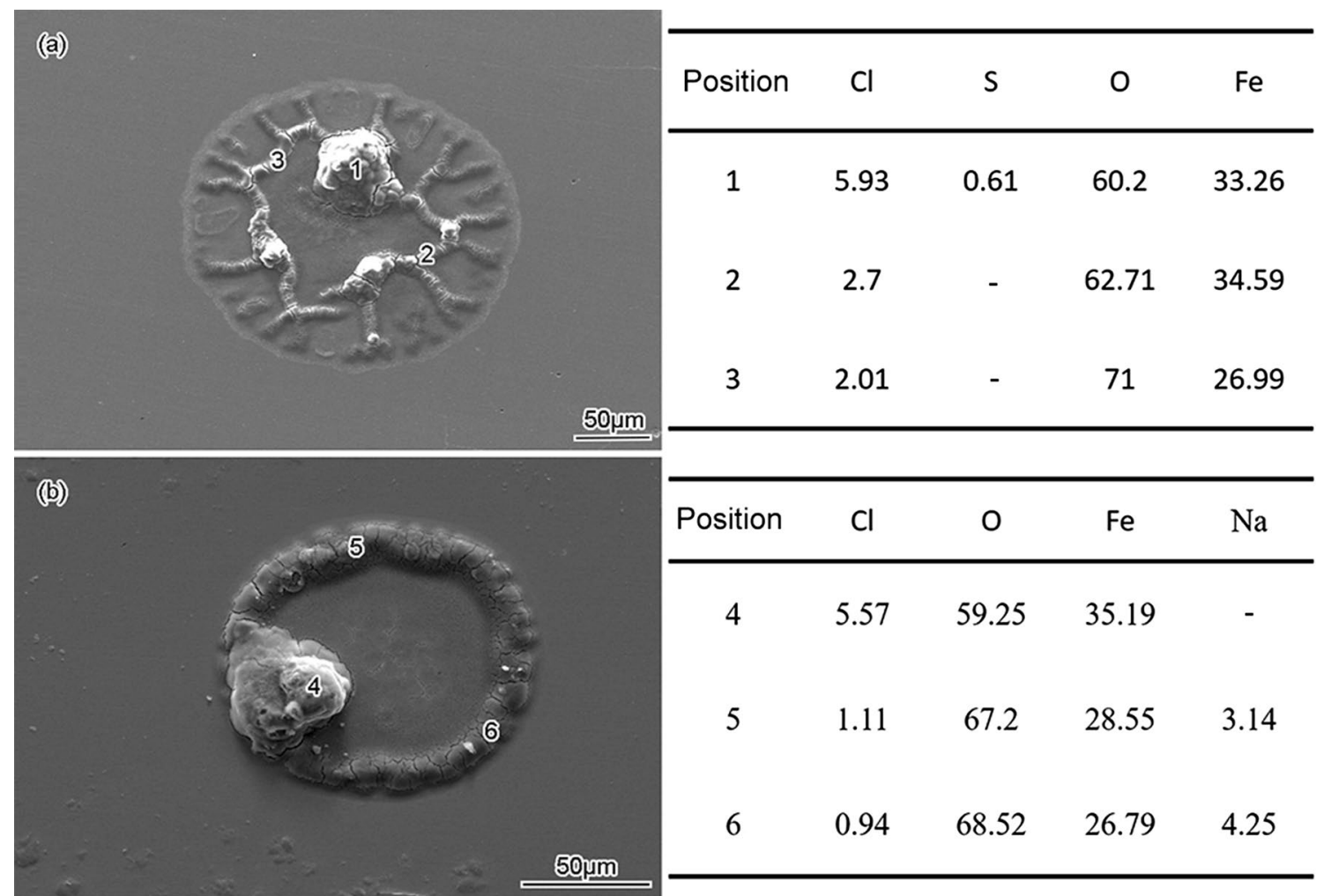

Fig. 11 Corrosion morphologies and element composition under acidified droplet with $\mathrm{pH}=1$ : $\mathbf{a} \mathrm{H}_{2} \mathrm{SO}_{4} ; \mathbf{b ~} \mathrm{HCl}$

(a)

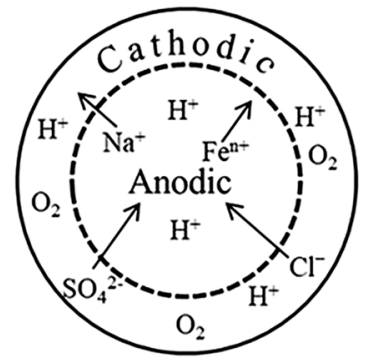

(c)

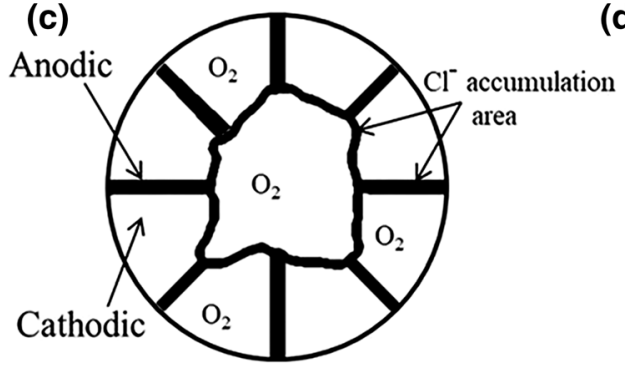

Fig. 12 Schematic diagram of formation process of ridge-like morphology under droplet acidified by $\mathrm{H}_{2} \mathrm{SO}_{4}$ : a anode and cathode formed under droplet. $\mathrm{Na}^{+}$and $\mathrm{Fe}^{n+}$ migrated to the cathode area; $\mathrm{Cl}^{-}$and $\mathrm{SO}_{4}{ }^{2-}$ moved toward the anode area; $\mathbf{b}$ radial segregation of $\mathrm{Cl}^{-}$in the periphery of the droplet. The segregation area acted as (b)

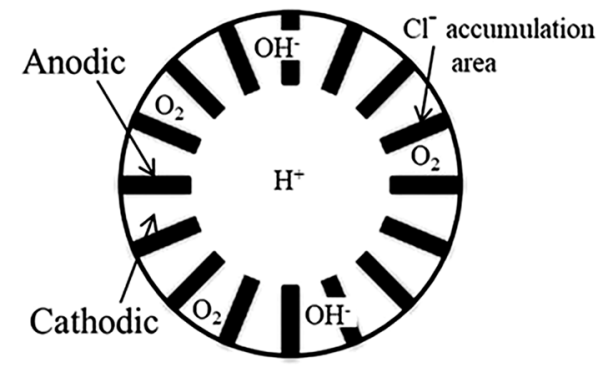

(d)

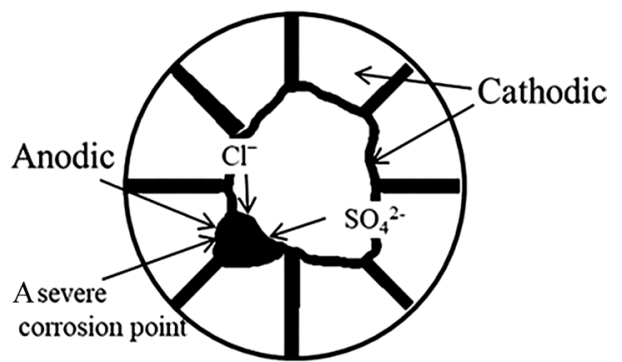

local anode and corrosion products deposited on the accumulation area firstly; $\mathbf{c}$ a raised irregular corrosion products ring formed in the end of radial corrosion products. The raised corrosion products will absorb more water and $\mathrm{Cl}^{-} ; \mathbf{d}$ one or several weak points in raised corrosion products acted as anode forming a severe corrosion point 
center (Fig. 8c). The process is similar to the formation of filiform corrosion, where the $\mathrm{Cl}^{-}$concentrates in the head of the filament $[22,29]$. With the corrosion going on, because of the inhomogeneity of ring-like corrosion products, one or several weak points of the ring-like corrosion products corroded more severely than the other area (Fig. 8c), and the points that acted as the anode contained more anions than the other area for the migration of anions (Fig. 11).

When the $\mathrm{NaCl}$ droplets were acidified by $\mathrm{H}_{2} \mathrm{SO}_{4}$, there were also two different corrosion morphologies with different $\mathrm{pH}$. For the droplets acidified by $\mathrm{H}_{2} \mathrm{SO}_{4}$ with $\mathrm{pH}=2$ and 3 , the corrosion morphology was also uniform corrosion, and the corrosion mechanism was the same with the droplets acidified by $\mathrm{HCl}$ to $\mathrm{pH}=2$ and 3 . However, for the acidified droplets with $\mathrm{pH}=1$, the high concentration of $\mathrm{H}^{+}$caused the droplet to need more time to neutralize the environment. As for the anion migration process under the droplet, $\mathrm{SO}_{4}{ }^{2-}$ had a competitive effect on the migration of $\mathrm{Cl}^{-}$, and these two anions inevitably collided with each other during the migration process from the perimeter to the center of the droplet. The radius and mass of $\mathrm{SO}_{4}{ }^{2-}$ were greater than those of $\mathrm{Cl}^{-}$, so the collision between them can easily change the migration direction of $\mathrm{Cl}^{-}$and cause radial segregation in the perimeter area. For the segregation area, the high concentration of $\mathrm{Cl}^{-}$decreases the solubility of oxygen and forces oxygen to move to the adjacent area, which hinders the diffusion of oxygen to the center $[29,35]$. Also, the high concentration of $\mathrm{Cl}^{-}$in the segregation area forms a local anode. With the increase of $\mathrm{pH}$ in the perimeter area, corrosion products first were deposited on the segregation area of $\mathrm{Cl}^{-}$; hence, radial products were observed in the experiment (Fig. 12b). For filiform corrosion, the filaments initiated from the periphery of the droplets and grew away from the original droplets irregularly $[23,29,30]$. $\mathrm{As} \mathrm{Cl}^{-}$and $\mathrm{SO}_{4}{ }^{2-}$ moved to the center of the droplet, because of the higher ion mobility coefficient for $\mathrm{Cl}^{-}$compared with that of $\mathrm{SO}_{4}{ }^{2-}$ [36], the content of $\mathrm{Cl}^{-}$increased, and the collision could not cause segregation of $\mathrm{Cl}^{-}$; then, the radial products stopped growing. Furthermore, the diffusion of oxygen under the droplets was hindered, which slowed the increase of $\mathrm{pH}$ of the center, and the corrosion products could not deposit, resulting in the formation of ring-like raised corrosion products (Fig. 12c). With the increase of corrosion time, a small number of corrosion products were also deposited on the other area. As mentioned above, the corrosion products are porous, and they absorb water and $\mathrm{Cl}^{-}$from the nearby area (Fig. 10). Hence, the high content of $\mathrm{Cl}^{-}$led these areas to act as the anode and resulted in a faster corrosion rate (Fig. 8a). The faster corrosion rate resulted in accumulation of more corrosion products, forming a ridge-like corrosion morphology. One or several severe corrosion points were also observed under the droplet, and the formation mechanism was the same, with the point formed under the droplet acidified by $\mathrm{HCl}$ (Fig. 12d).

The formation of the ridge-like morphology is the result of the synergistic effect of $\mathrm{pH}$ and $\mathrm{SO}_{4}{ }^{2-}$. For the droplets acidified with $\mathrm{pH}=2$ and 3 , even with a high concentration of $\mathrm{SO}_{4}{ }^{2-}$ (Fig. 5), ridge-like morphologies were not observed, because there was not enough time for the segregation of $\mathrm{Cl}^{-}$. For the droplets with $\mathrm{pH}=1$ with a low concentration of $\mathrm{SO}_{4}{ }^{2-}$ (Fig. 6), ridge-like morphologies were not observed as well, because the collision between the two anions could not cause the segregation of $\mathrm{Cl}^{-}$. Therefore, a lower $\mathrm{pH}$ and a certain amount of $\mathrm{SO}_{4}{ }^{2-}$ are the essential conditions to form the ridge-like morphology.

Because of the geometry of small-particle-size droplets, the diffusion distance of oxygen is shorter, and the potential difference between the center and periphery is smaller [29]. The shorter diffusion distance of oxygen benefits the increase of $\mathrm{pH}$, and less time is needed before the deposition of corrosion products. Therefore, the rate of formation of the ridge-like morphology was faster compared with that of large-particle-size droplets. In addition, a smaller potential difference between the center and periphery means a smaller drive of the migration of anions, and it follows that the length of radial products was shorter in the periphery.

\section{Conclusions}

(1) $\mathrm{NaCl}$ aerosol droplets acidified by $\mathrm{HCl}$ and $\mathrm{H}_{2} \mathrm{SO}_{4}$ with the diameter ranging from 50 to $250 \mu \mathrm{m}$ were deposited on the surface of Q235 carbon steel. The acidification of $\mathrm{NaCl}$ aerosol droplets could change the corrosion morphology of carbon steel. For the acidified aerosol droplets, the filiform corrosion was inhibited, and the corrosion morphologies depend on the $\mathrm{pH}$ and acidified type.

(2) When the aerosol droplets were acidified with $\mathrm{pH}=2$ and 3 , the corrosion morphologies were general corrosion for both acidifiers. When the droplets were acidified by $\mathrm{HCl}$ with $\mathrm{pH}=1$, the ring-like corrosion morphologies formed for more $\mathrm{Cl}^{-}$concentrated on the perimeter. For the aerosol droplets acidified by $\mathrm{H}_{2} \mathrm{SO}_{4}$ with $\mathrm{pH}=1$, the lower $\mathrm{pH}$ made the segregation of $\mathrm{Cl}^{-}$ possible because of the collision between $\mathrm{SO}_{4}{ }^{2-}$ and $\mathrm{Cl}^{-}$during the migration. The corrosion products precipitated on the segregation area of $\mathrm{Cl}^{-}$first and then formed the ridge-like morphology.

(3) The size of the droplets also influenced the ridge-like corrosion morphology. The smaller droplets showed a faster rate of formation and shorter raised radial products. 
Acknowledgements This work was supported financially by the National Natural Science Foundation of China (Nos. 51671197 and 51601199) and the Guangzhou Industry-University-Research Collaborative Innovation Alliance Special Project (No. 201604046014).

\section{References}

[1] C. Lin, Q. Zhao, Y.E. Liu, J.N. Liang, Acta Metall. Sin. 46, 358 (2010). (in Chinese)

[2] S. Oesch, Corros. Sci. 38, 1357 (1996)

[3] J.E. SvenssonL, G. Johansson, Corros. Sci. 34, 721 (1993)

[4] T.E. Graedel, R.P. Frankenthal, J. Electrochem. Soc. 137, 2385 (1990)

[5] T. Tsuru, A. Nishikata, J. Wang, Mater. Sci. Eng. A 198, 161 (1995)

[6] R. Lindstrom, J.E. Svensson, L.G. Johansson, J. Electrochem. Soc. 147, 1751 (2000)

[7] J.E. Svensson, L.G. Johansson, Corros. Sci. 38, 2225 (1996)

[8] I.S. Cole, N.S. Azmat, A. Kanta, M. Venkatraman, Int. Mater. Rev. 54, 117 (2009)

[9] I.S. Cole, W.D. Ganther, D. Lau, Corros. Eng. Sci. Technol. 41, 310 (2006)

[10] I.S. Cole, W.D. Ganther, D.A. Paterson, G.A. King, S.A. Furman, D. Lau, Corros. Eng. Sci. Technol. 38, 259 (2003)

[11] G. Hoelzl, G. Luckeneder, H. Duchaczek, C. Kleber, A.W. Hassel, Corros. Sci. 127, 222 (2017)

[12] N.S. Azmat, K.D. Ralston, B.C. Muddle, I.S. Cole, Corros. Sci. 53, 3534 (2011)

[13] N.S. Azmat, K.D. Ralston, B.C. Muddle, I.S. Cole, Corros. Sci. 53, 1604 (2011)

[14] A.K. Neufeld, I.S. Cole, A.M. Bond, S.A. Furman, Corros. Sci. 44, 555 (2002)

[15] Z.Y. Chen, D. Persson, C. Leygraf, Corros. Sci. 50, 111 (2008)
[16] E. Schindelholz, B.E. Risteen, R.G. Kelly, J. Electrochem. Soc. 161, C460 (2014)

[17] L. Shengxi, L.H. Hihara, J. Electrochem. Soc. 159, C461 (2012)

[18] Z.Y. Chen, D. Persson, F. Samie, S. Zakipour, C. Leygraf, J. Electrochem. Soc. 152, B502 (2005)

[19] J. Alcantara, D.D.L. Fuente, B. Chico, J. Simancas, I. Diaz, M. Morcillo, Materials 10, 64 (2017)

[20] N.T. Lau, C.K. Chan, L.I. Chan, M. Fang, Corros. Sci. 50, 2927 (2008)

[21] I.S. Cole, D. Lau, D.A. Paterson, Corros. Eng. Sci. Technol. 39, 209 (2004)

[22] S.X. Li, L.H. Hihara, Corros. Eng., Sci. Technol. 45, 49 (2010)

[23] B.E. Risteen, E. Schindelholz, R.G. Kelly, J. Electrochem. Soc. 161, C580 (2011)

[24] S. Li, L.H. Hihara, J. Electrochem. Soc. 161, C268 (2014)

[25] B.E. Risteen, E. Schindelholz, R.G. Kelly, ECS Trans. 58, 1 (2014)

[26] S. Li, L.H. Hihara, Corros. Sci. 108, 200 (2016)

[27] C. Chen, F. Mansfeld, Corros. Sci. 39, 409 (1997)

[28] C. Chen, C.B. Breslin, F. Mansfeld, Mater. Corros. 49, 569 (1998)

[29] J. Weissenrieder, C. Leygraf, J. Electrochem. Soc. 151, B165 (2004)

[30] W. Han, G.C. Yu, Z.Y. Wang, J. Wang, Corros. Sci. 49, 2920 (2007)

[31] S.R. Street, A. Cook, H.B. Mohammed-Ali, T. Rayment, A.J. Davenport, Corrosion 74, 520 (2018)

[32] I.S. Cole, D.A. Paterson, W.D. Ganther, Corros. Eng. Sci. Technol. 38, 129 (2003)

[33] I.S. Cole, Materials 10, 12 (2017)

[34] J. Weissenrieder, C. Kleber, M. Schreiner, C. Leygraf, J. Electrochem. Soc. 151, B497 (2004)

[35] B. Maier, G.S. Frankel, J. Electrochem. Soc. 157, C302 (2010)

[36] S.I. Pyun, K.H. Na, J.J. Park, J. Solid State Electrochem. 5, 473 (2001) 